Volume 9. No. 4, April 2021

International Journal of Emerging Trends in Engineering Research

Available Online at http://www.warse.org/IJETER/static/pdf/file/ijeter11942021.pdf

https://doi.org/10.30534/ijeter/2021/11942021

\title{
Numerical Analysis Natural Convection Heat Transfer from Vertical Cylinder Annular Fins with The Addition of Slits
}

\author{
Jiki Hikmatullah $^{1}$, Slamet Wahyudi ${ }^{2}$, Putu Hadi Setyorini ${ }^{3}$ \\ ${ }^{1}$ University of Brawijaya, Indonesia, jikihikmatullah80@ gmail.com \\ ${ }^{2}$ Univeristy of Brawijaya, Indonesia, slamet_w72@ub.ac.id \\ ${ }^{3}$ University of Brawijaya, Indonesia, putu_hadi@ub.ac.id
}

\begin{abstract}
One method of increasing the heat transfer rate of the fins is by adding slits to the fins. The purpose of this study was to analyze the heat transfer rate by adding slits in the annular fins with a vertical cylinder under natural convection conditions. The vertical cylinder length, cylinder diameter, fin diameter, and distance between the fins are $313 \mathrm{~mm}, 25$ $\mathrm{mm}, 125 \mathrm{~mm}$, and $7 \mathrm{~mm}$, respectively. The number of slits varied from 2 slits and 4 slits and the spacing of the slits was kept constant by $5 \mathrm{~mm}$. This research was conducted with a simulation method using Autodesk CFD 2019 software. As a result, fins with slits and fins without slits were compared. The value of the heat transfer rate that occurs and the heat transfer coefficient in the annular fin with slits is better than the fin without slits. The highest heat transfer rates were $142.928 \mathrm{~W}$ and $2.6022 \mathrm{~W} / \mathrm{m}^{2} \mathrm{~K}$ for an annular fin with 2 slits
\end{abstract}

Key words: Annular Fin, Heat Transfer, Natural Convection, Slits.

\section{INTRODUCTION}

There are two types of cooling methods: natural convection and forced convection cooling methods. The advantage of using the natural convection cooling method is that there is no need for additional components such as a fan in the forced convection cooling method. So that this method does not require extra maintenance and the cost used is cheaper. The forced convection cooling method has a better heat transfer rate than the natural convection cooling method as described by Kreith et al [1]. Using fins is one way to solve this problem. One of the most commonly used fins is annular fins because the manufacturing process and analysis are simpler.

There is a great deal of literature on heat transfer by natural convection including Churchill and chu [2] and Churchill [3]. The author conducted experiments and obtained an equation to determine the mean Nusselt number as a function of Prandalt and Rayleigh numbers for natural convection in a horizontal cylinder and vertical flat plate.
To determine the Nusselt number in the vertical cylinder, you can use the equation for the vertical flat plate because both have the same equation as described by Holman [4]. To prevent the curvature effect Minkowycz and Sparrow [5] developed a local non-similarity solution method to solve cases of natural convection in vertical cylinders with high curvature.

The use of fins to increase the heat transfer rate extensively has been studied by Guvenc and Yuncu [6] and Yildiz and Yuncu [7]. A numerical study of natural convection heat transfer from vertical cylinders with annular fin has been carried out by Senapati et al [8]. This study compared the effect of the fin-to-tube diameter ratio (D / d) and fin spacing to tube diameter ratio (L / d) for laminar and turbulent conditions with ranges 2-5 and 0.126-5.840, respectively. Numerical simulations of the Navier-Stokes equations and energy equations have been carried out for the vertical cylinder with the annular fin using the algebraic multi-grid solver of FLUENT 15. They found that the optimum fin distance where the maximum heat transfer rate for turbulent flow is between $\mathrm{s} / \mathrm{d}=0.28$ to 0.31 or $7 \mathrm{~mm}$ to $7.7 \mathrm{~mm}$.

To increase the heat transfer rate in the fins, many researchers change the geometric shape and direction of its orientation as was done by Shyy-Woei Chang et al [9]. The authors numerically examined the effect of dimples on vertical fin arrays for natural convection. The finite volume method is used to solve the energy and Navier-Stokes equations. A semi-implicit method for pressure-linked equation (SIMPLE) is used in CFD analysis to obtain data in the form of temperature, velocity, and Nusselt number. This study uses four different Rayleigh numbers with fixed Prandtl numbers to analyze the thermal performance of natural convection in vertical fin arrays. The result shows that the thermal efficiency of the fin array with dimple increases with the same fin base area and fin-array volume conditions. The value of the Nusselt number shows an increase with the increase in the value of the Rayleigh number in the fin array with the dimple. Dimpled fin array with 9 configurations shows a maximum increase of 68\% compared to plain fin array with 13 fins. Experimental studies have been carried out by Park et al [10] on vertical cylinders with branched fins for cases of natural 
convection. This research was conducted by examining the effect of branch angle, fin numbers, and fin base temperatures.

From the experimental data, the authors obtained the equation to determine the Nusselt number for the range of Rayleigh number, branch angle, and the number of consecutive fin $100000-600000,10-40^{\circ}$ and 9-36 fins. From this equation, a contour map will be obtained that describes the thermal resistance as a function of the number of fins and thickness of the fins. The results of this study show that the cylinder with branch fins shows $36 \%$ lower thermal resistance than the cylinder with plate fins.

Al-Doori [11] experimented to increase the heat transfer rate in the rectangular fin by using circular perforations. The number of holes used in this study consisted of 24-56 holes. The hole pattern used starts from 24 holes for the first fin and the number of holes increases by 8 holes for the next fin. The holes are arranged into 6-14 rows and 4 columns. The results show that the fin perforated has a lower temperature than the fin without holes. This temperature decreases with increasing hole diameter. The highest temperature drop occurred at the maximum heat input $(220 \mathrm{~W})$ from 250 to $49^{\circ} \mathrm{C}$ for the fin without holes and from 250 to $36^{\circ} \mathrm{C}$ for the perforated fin. The heat transfer rate and heat transfer coefficient increase as the number of holes increases.

An experimental study to increase the rate of natural convection heat transfer in rectangular fin arrays using holes and tilt angle has been carried out by Awasarmol and Pise [12]. The diameter of the hole used is varied from 4-12 mm and the angle of inclination from $0-90^{\circ}$. The results of this study show that using holes can increase the rate of heat transfer that occurs. The value of the heat transfer coefficient on the fin perforated with a diameter of $12 \mathrm{~mm}$ increased by $32 \%$ compared to the solid fin array and almost saved $30 \%$ on material usage.

No research explains the effect of adding slits in the fin with the annular type. Therefore, this study will discuss the effect of the slits on the rate of heat transfer in a vertical cylinder with an annular fin under natural convection conditions.

\section{PROBLEM DESCRIPTION}

This research was conducted using a simulation method using Autodesk CFD 2019. The main objective is to compare the thermal performance between the slit and slitless fins. The dimensions of the model to be used include cylinder diameter, fin diameter, cylinder length, the distance between fins and fin thickness, respectively, $25 \mathrm{~mm}, 125 \mathrm{~mm}, 313 \mathrm{~mm}, 7 \mathrm{~mm}$, and $1 \mathrm{~mm}$. The number of slits used was 2 and 4 slits and the spacing of the slits was $5 \mathrm{~mm}$. The inside of the cylinder will be given a constant temperature with variations of $50^{\circ} \mathrm{C}$, $60^{\circ} \mathrm{C}, 70^{\circ} \mathrm{C}, 80^{\circ} \mathrm{C}$, and $90^{\circ} \mathrm{C}$. The material used is aluminum because it has high thermal conductivity. From the simulation results, the temperature distribution and convection heat transfer rate at the fin will be obtained for each model
The boundary condition used is the pressure boundary condition to define an opening at the top and bottom. At the inlet (bottom face), the temperature boundary condition is also used as the ambient temperature is $30^{\circ} \mathrm{C}$.

On the inside of the cylinder used temperature boundary conditions according to the temperature variations used. The governing equation of conservation of mass, momentum, and energy is solved by considering mixing length models. Figure 1 shows the isometric view of the annular fin used in this study. Figure 2 shows the size of the external volume used. Figure 3 shows the boundary conditions used.

\section{MATHEMATICAL MODELING}

The flow is assumed to be steady, the Rayleigh number is used to determine laminar or turbulent flow and the fluid is assumed to be incompressible. Environmental air is defined as an ideal incompressible gas. Other properties are considered constant. The equations used in this simulation include:

Continuity equations for stable and non-compressible flow:

$$
\frac{\partial u}{\partial x}+\frac{\partial v}{\partial y}+\frac{\partial w}{\partial z}=0
$$

momentum equations :

$$
\begin{aligned}
& u \frac{\partial u}{\partial x}+v \frac{\partial u}{\partial y}+w \frac{\partial u}{\partial z}=-\frac{1}{\rho} \frac{\partial p}{\partial x}+v\left(\frac{\partial^{2} u}{\partial x^{2}}+\frac{\partial^{2} u}{\partial y^{2}}+\frac{\partial^{2} u}{\partial z^{2}}\right) \\
& u \frac{\partial v}{\partial x}+v \frac{\partial v}{\partial y}+w \frac{\partial v}{\partial z}=-\frac{1}{\rho} \frac{\partial p}{\partial y}+v\left(\frac{\partial^{2} v}{\partial x^{2}}+\frac{\partial^{2} v}{\partial y^{2}}+\frac{\partial^{2} v}{\partial z^{2}}\right) \\
& \text { dan } \\
& u \frac{\partial w}{\partial x}+v \frac{\partial w}{\partial y}+w \frac{\partial w}{\partial z}=-\frac{1}{\rho} \frac{\partial p}{\partial z}+v\left(\frac{\partial^{2} w}{\partial x^{2}}+\frac{\partial^{2} w}{\partial y^{2}}+\frac{\partial^{2} w}{\partial z^{2}}\right)
\end{aligned}
$$

Energi equations :

$$
u \frac{\partial T}{\partial x}+v \frac{\partial T}{\partial y}+w \frac{\partial T}{\partial z}=\alpha\left(\frac{\partial^{2} T}{\partial x^{2}}+\frac{\partial^{2} T}{\partial y^{2}}+\frac{\partial^{2} T}{\partial z^{2}}\right)
$$

From the simulation results, the value of the heat transfer rate and the average temperature will be obtained. These two values are used to determine the value of the heat transfer coefficient according to Newton's Law Cooling as follows $\mathrm{h}=\mathrm{Q} / \mathrm{A}\left(\left(\mathrm{T}_{\mathrm{w}}-\mathrm{T}_{\infty}\right)\right.$ $\mathrm{Q}, \mathrm{A}, \mathrm{T}_{\mathrm{w}}$, and $\mathrm{T}_{\infty}$ are the heat transfer rate, surface area, average temperature, and ambient temperature. 


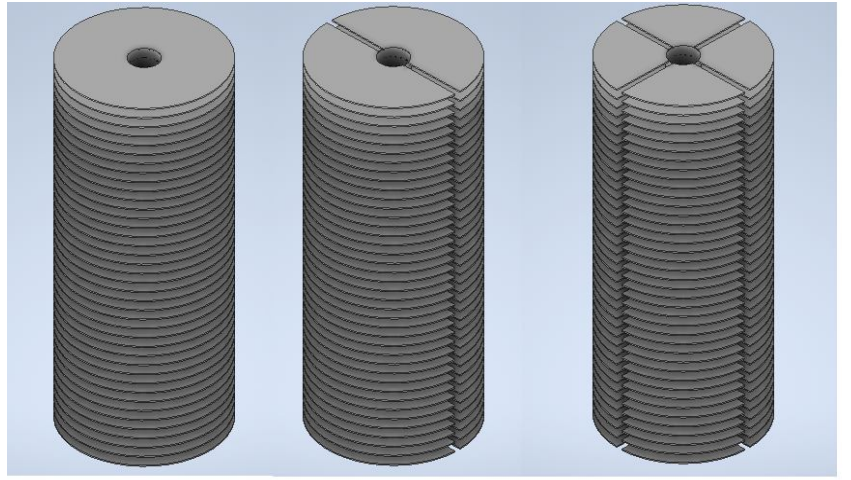

Figure 1: 3D view of a vertical cylinder with annular fins

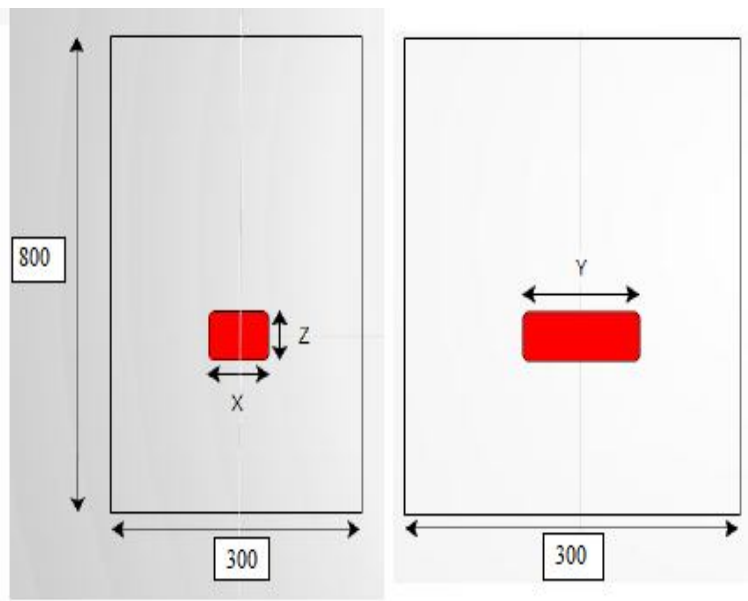

Figure 2: Dimensions of external volume

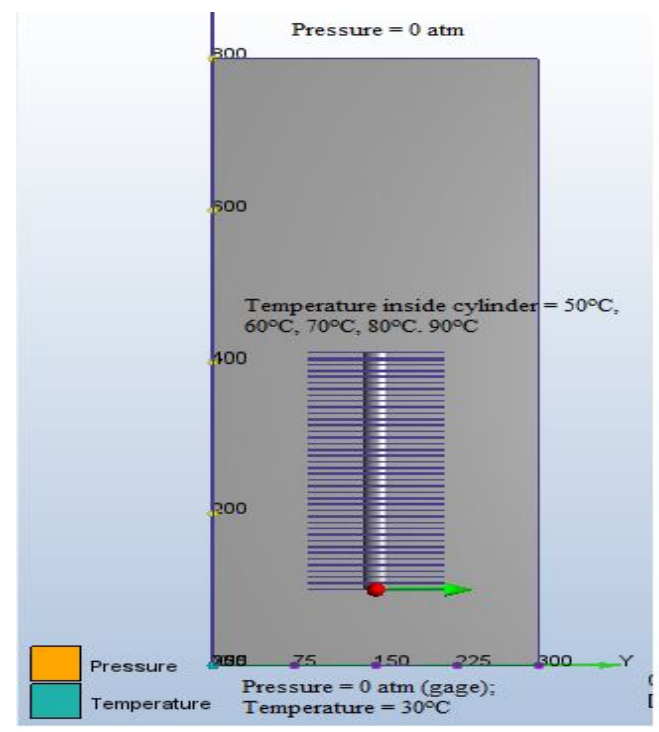

Figure 3: Boundary Condition

\section{VERIFICATION}

The simulation results are compared with experimental equations based on the literature. The heat transfer coefficient is determined using the following equation:
$\mathrm{Nu}=\frac{h L}{k}$

Nusselt numbers are determined using the Churchill equation [3]:

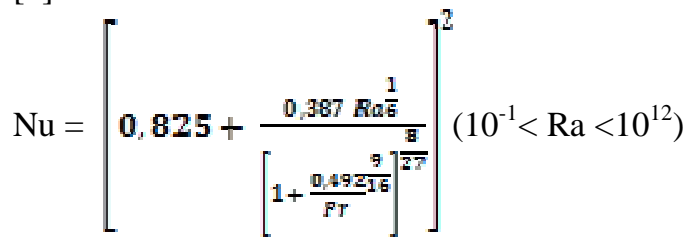

The equation is used if the value

$\frac{d}{l} \geq \frac{35}{\mathrm{Gr}_{l}^{\frac{1}{4}}}$

For the value obtained that is not following equation 8 , you can still use equation 6 but you have to multiply by a factor of F as explained by Minkowycz and Sparrow [5] for gas with Pr $=0.7$ i.e.

$\mathrm{F}=1.3\left[(\mathrm{~L} / \mathrm{d}) / \mathrm{Gr}_{\mathrm{d}}\right]^{1 / 4}+1.0$

The Rayleigh number is obtained using the equation below

$\mathrm{Ra}=\frac{g \beta\left(T_{s}-T_{w}\right) L^{3} p_{r}}{v}$

$\mathrm{B}, v$, and Pr are thermal expansion, kinematic viscosity, and Prandtl Number. The value is determined based on the temperature of the film, $T_{f}=\left(T_{w}-T \infty\right) / 2$. Figure 4 shows the comparison of the simulated and experimental heat transfer coefficient values by Churchill. The graph shows that the simulation results are close to the experimental results with a maximum deviation of $10.8 \%$.

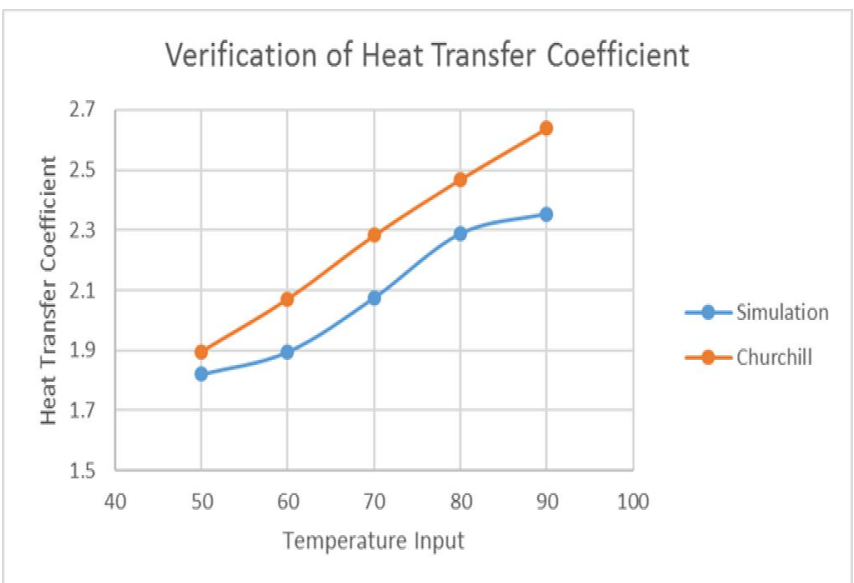

Figure 4: comparison of heat transfer coefficients of simulated and experimental results by Churchill

\section{RESULT AND DISCUSSION}

\subsection{Comparison of Heat Transfer Rate}

Numerical simulations were carried out to determine the effect of the slits on the thermal performance of the vertical cylinder with the annular fin. The inside of the cylinder is 
given a temperature variation. The temperatures used were $50^{\circ} \mathrm{C}, 60^{\circ} \mathrm{C}, 70^{\circ} \mathrm{C}, 80^{\circ} \mathrm{C}$, and $90^{\circ} \mathrm{C}$. The number of slits used was 2 and 4 slits. The spacing of slits used is $5 \mathrm{~mm}$. Natural convection is caused by the buoyancy effect. The slits influence the rate of heat transfer that occurs in the vertical cylinder with the annular fin. Figure 5 shows the total heat flux for each fin model. It appears that fins with slits have a higher value than fins without slits. The highest total heat flux is $142.928 \mathrm{~W}$ for fins with 2 slits. The presence of slits increases turbulence in the airflow inside the fin.

\subsection{Comparision of Heat Transfer Coefficient}

From the discussion in the previous section, it is known that the slits have a role in the rate of heat transfer that occurs in the vertical cylinder with the annular fin. This section will discuss the effect of the slits on the value of the heat transfer coefficient. Figure 6 shows the comparison of the heat transfer coefficient of each model. It appears that the slit fins have a better heat transfer coefficient than the slitless fins. The highest heat transfer coefficient is $2.6022 \mathrm{~W} / \mathrm{m}^{2} \mathrm{~K}$ for fins with 2 slits. This is because the average temperature value for slit fins is lower due to more turbulence. Increased turbulence will increase the thermal performance of the fin. The temperature of the vertical cylinder with the annular fin for the fin without the slits and the fin with the slits are shown in Figure 7. The simulation results show that the airflow moves from the bottom up due to the buoyancy effect. The heat from the fins is transferred to the air, causing the air temperature to rise. Increasing the air temperature causes the density of the air to get smaller so that there is a movement of airflow from the bottom to the top.

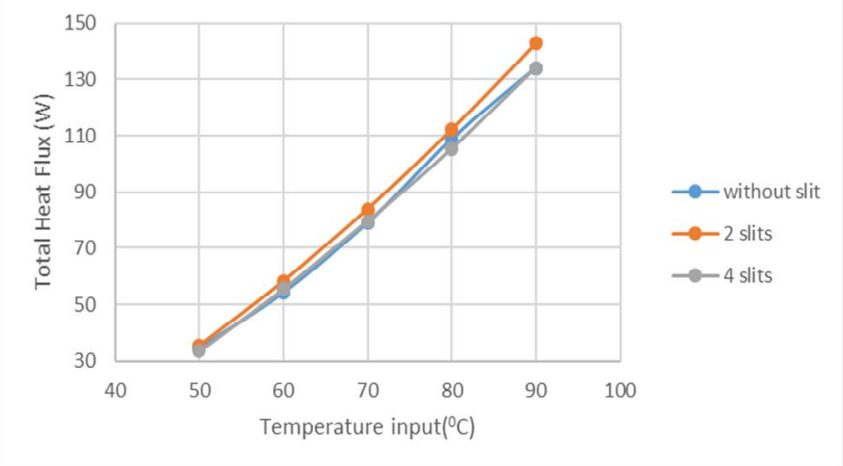

Figure 5: Comparison of Total Heat Flux

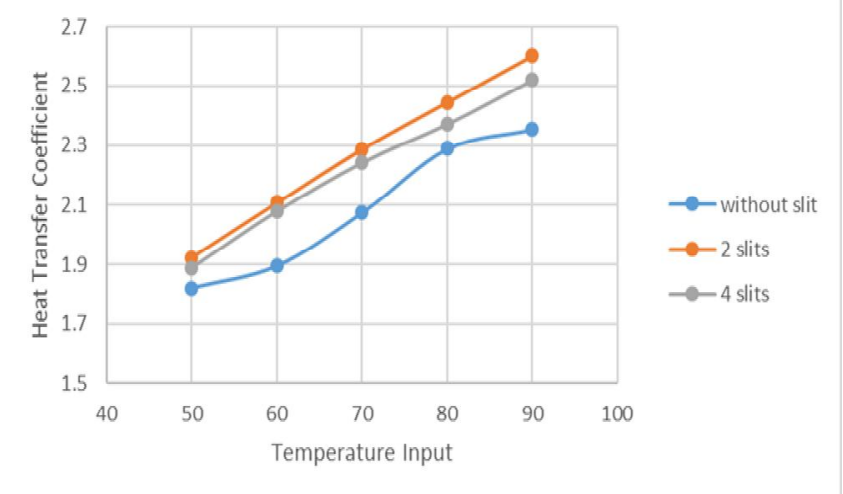

Figure 6: Comparison of Heat Transfer Coefficient

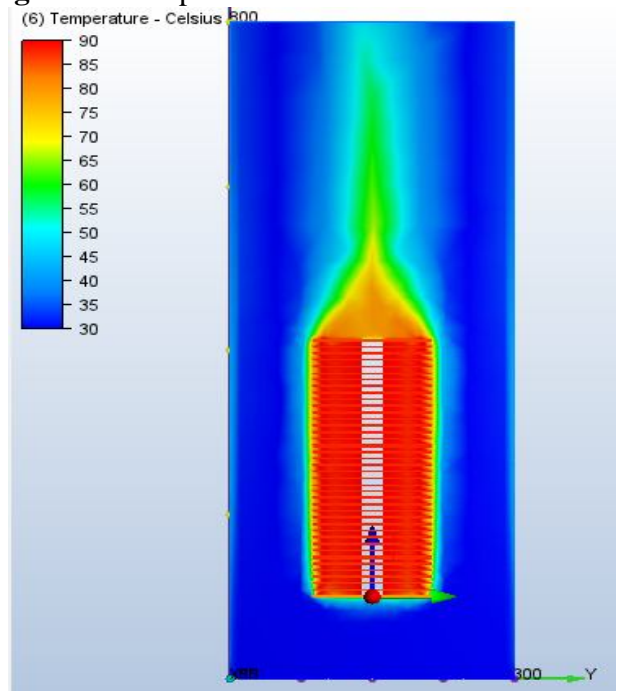

(a)

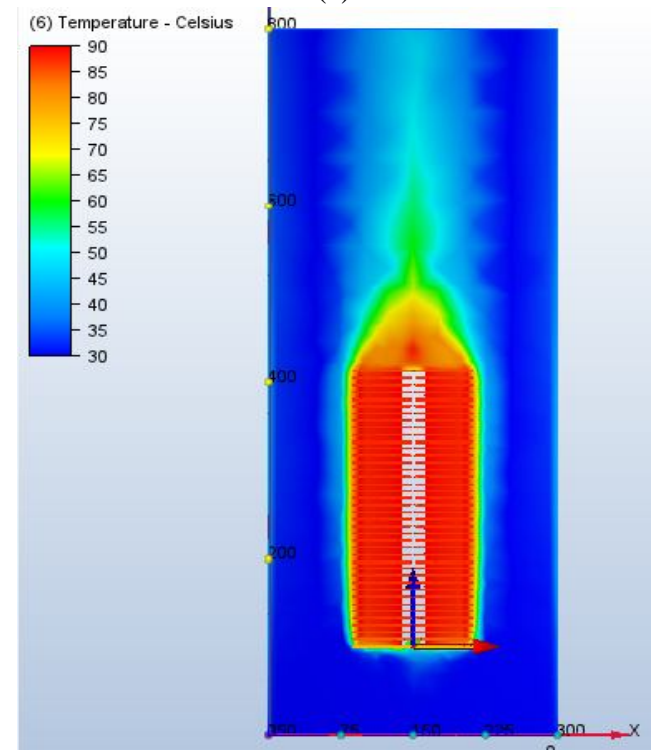

(b) 


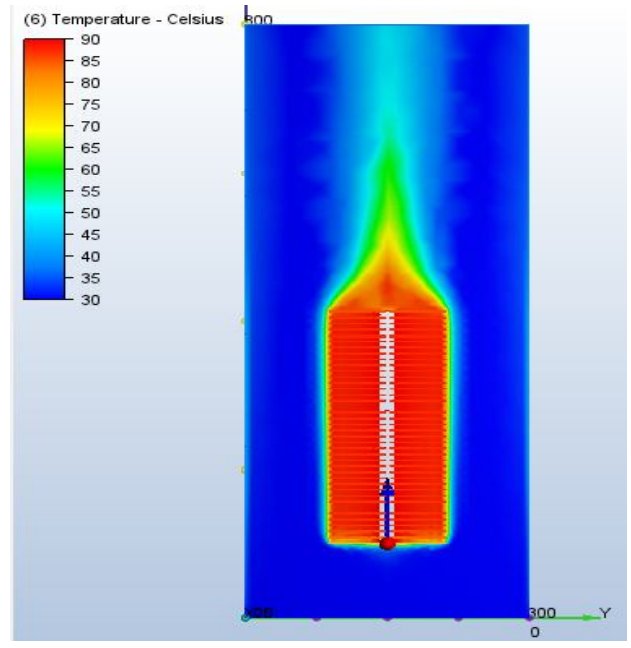

(c)

Figure 7: The temperature profile in annular fin and air for different number of slits at $90^{\circ} \mathrm{C}$; (a) without slits; (b) 2 slits; (c) 4 slits

\section{CONCLUSION}

This study has compared the thermal performance between the vertical cylinder and annular fin with slits and without slits using Autodesk CFD 2019 software. The results show that using slits in the vertical cylinder with an annular fin can increase the rate of heat transfer. This happens because of the increase in turbulence which makes the average temperature lower.

\section{REFERENCES}

[1] F. Kreith, R. M. Manglik dan M. S. Bohn, "Principle of Heat transfer Seventh Edition," Stamford, Cengage Learning, 2011.

[2] S. W. Churchill dan H. H. Chu, "Correlating Equations for laminar and Turbulent Free Convection From A Horizontal Cylinder," Heat Mass Transfer, vol. 18, pp. 1049-1055, 1975.

[3] S. W. Churchill, "A Comprehensive Correlating Equation for Laminar Assisting Forced and Free Convection," AIChE Journal, vol. 23, pp. 10-16, 1977.

[4] J. P. Holman, Heat Transfer, Tenth Edition., New York: Mc-Graw Hill Higher Education, 2011.

[5] W. J. minkowycz dan E. M. Sparrow, "Local Nonsimilar Solutions for Natural Convection on a Vertical Cylinder," Heat Transfer, vol. 96, no. 2, pp. 178-183, 1974.

[6] A. Guvenc dan H. Yuncu, "An experimental investigation on performance of fins on a horizontal base in free convection heat transfer," Heat and Mass Transfer, vol. 37, pp. 409-416, 2001.

[7] S. Yildiz dan H. Yuncu, "An experimental investigation on performance of annular fins on a horizontal cylinder in free convection heat transfer," Heat and Mass Transfer, vol. 40, pp. 239-251, 2004.
[8] J. R. Senapati, S. K. Dash dan S. Roy, "Numerical investigation of natural convection heat transfer from vertical cylinder with annular fins," International Journal of Thermal Sciences, vol. 111, pp. 146-159, 2017.

[9] S.-W. Chang, "Heat transfer enhancement of vertical dimpled fin array in natural convection," International Journal of Heat and Mass Transfer, 2016.

[10] K. T. Park, H. J. Kim dan D. K. Kim, "Experimental study of natural convection from vertical cylinders with branched fins," Experimental Thermal and Fluid Science, vol. 54, pp. 29-37, 2014.

[11] W. H. Al-Doori, "Enhancement of Natural Convection Heat Transfer From Rectangular Fins By Circular Perforations," International Journal of Automotive and Mechanical Engineering, vol. 4, pp. 428-436, 2011.

[12] U. V. Awasarmol dan A. T. Pise, "An experimental investigation of natural convection heat transfer enhancement from perforated rectangular fins array at different inclinations," Experimental Thermal and Fluid Science, vol. 68, pp. 145-154, 2015. 